recorded the temperature. The prescription and administration of drugs were recorded in separate places, and admission information recorded on a brief proforma.

Although the job aides received positive endorsement during the EPCP courses there has been some resistance to their use in the wards. A survey of patient notes at one site demonstrated that no staff were using the admission forms or the drug charts adequately. Vital signs charts were more acceptable and $100 \%$ were satisfactory.

Healthcare workers considered the job aides useful, but cited poor staffing and lack of time as the reason for limited acceptance. Suggestions included:

- Senior endorsement

- Training for all staff on how to use the job aides

- Explanation to nurses how vital signs charts can be used to monitor patient progress and signal when to get help

Conclusion Job aides can focus the attention of healthcare workers on key signs and symptoms as taught in EPCP. Ongoing training, familiarisation, mentorship and support from senior colleagues will be key for their successful introduction.

\section{G274(P) STABILISATION, REFERRAL \& TRANSFER OF ACUTELY UNWELL CHILDREN IN MYANMAR}

${ }^{1,2} \mathrm{~J}$ Halbert, ${ }^{2} \mathrm{M}$ Malley, ${ }^{2} \mathrm{M}$ Monaghan, ${ }^{2} \mathrm{E}$ Roche, ${ }^{2} \mathrm{P}$ Babu, ${ }^{2} \mathrm{~S} \mathrm{Oo},{ }^{2} \mathrm{~J}$ Bowyer, ${ }^{2} \mathrm{M}$ Wooton. ${ }^{1}$ Paediatrics, University College London, London, UK; ${ }^{2}$ Global Child Health, RCPCH, London, UK

\subsection{6/archdischild-2018-rcpch.266}

Aims An Emergency Paediatric Care Programme in Myanmar provides training in the stabilisation and safe transfer of sick children. The transfer of seriously sick children may be necessary to ensure the appropriate level of care, but is fraught with difficulties. A review of current practice and local challenges was undertaken.

Methods In September 2015 a retrospective audit of children admitted with dengue to a Regional Centre was performed to identify reasons for referral. Local healthcare professionals were invited to complete a survey exploring barriers to referral pathways.

Results $34 \%$ of patients with dengue $(n=269)$ were referred. Only $44 \%$ of referrals had a referral letter and $35 \%$ did not require tertiary care.

Challenges identified included:

- Late presentation due to families' preference for traditional medicine, concerns about the quality of public healthcare, medical and transport costs

- Lack of referral guidelines, human resources and training

- Transfer of patients who had not first been stabilised

- Reluctance to acknowledge the potential benefits of transfers

- Deficiency in ambulances such that patients were transferred by public transport

Solutions identified and implemented included:

- Development of referral guidelines and pathways

- Training in stabilisation and transfer

- Development of transfer checklists for emergency equipment and medications

- Identification of voluntary sector transport vehicles
- Identification of outpatient tertiary clinic appointments to reduce unnecessary acute referrals

Conclusions There is a deficiency in referral pathways between primary, secondary and tertiary healthcare facilities in Myanmar. Development of referral networks and the training of healthcare workers in the stabilisation and transfer of sick children is important to reduce morbidity and mortality.

\section{G275(P) A STRATEGY TO SUPPORT CHANGES IN CLINICAL CARE FOLLOWING TRAINING COURSES AT DISTRICT HOSPITALS IN MYANMAR: IMPLEMENTATION PLANS}

1,2J Halbert, ${ }^{2} \mathrm{M}$ Malley, ${ }^{2} \mathrm{M}$ Monaghan, ${ }^{2} \mathrm{E}$ Roche, ${ }^{2} \mathrm{P}$ Babu, ${ }^{2} \mathrm{~S} \mathrm{O} 0,{ }^{2} \mathrm{~J}$ Bowyer, ${ }^{2} \mathrm{M}$ Wooton, ${ }^{2}$ KT Sin. ${ }^{1}$ Paediatrics, University College London, London, UK; ${ }^{2}$ Global Child Health, RCPCH, London, UK

\subsection{6/archdischild-2018-rcpch.267}

Aims An Emergency Paediatric Care Programme (EPCP) runs training courses in district hospitals. We describe a strategy to support local leadership and develop teams responsible for devising and fulfilling individual implementation plans.

Methods During EPCP courses, participants review the hospital facilities and make recommendations for improvement. A local EPCP Champion (senior clinician) supported by an EPCP Team is responsible for identifying local priorities and developing an Implementation Plan to achieve these. They are asked to consider: layout, infrastructure, staffing, patient safety and infection control, drugs and equipment, staff numbers and training, patient records, clinical guidelines, and morbidity and mortality meetings. Additional support is provided through Global Link Volunteer (GLV) placements in the hospitals.

A bi-annual EPCP Champion and Team Conference provides an opportunity to share ideas and experiences, problem solve and discuss quality improvement projects.

Results GLVs, EPCP Champions and Teams representing 7 district hospitals reported on their Implementation Plans at the first EPCP Champion and Team Conference in July 2016. A wide range of topics were described including weekly simulation training, new guideline wall charts, well-equipped resuscitation areas, new admission and observation charts, improved infection control through the repair of broken sinks and provision of hand-gel and multi-disciplinary mortality meetings.

Feedback was extremely positive with the teams feeling motivated, empowered and rewarded for their efforts.

Conclusions Successful training depends on its impact in practice; the EPCP Champions and Team Conference demonstrated that the combined efforts of local EPCP Champions and Teams and GLVs in developing the Implementation Plans had led to valuable quality improvements.

\section{G276(P) NEONATAL MORTALITY IN WESTERN UGANDA}

${ }^{1} \mathrm{C}$ Harris, ${ }^{2} \mathrm{H}$ Patel, ${ }^{2} \mathrm{O}$ Corn, ${ }^{2} \mathrm{U}$ Harris, ${ }^{2} \mathrm{M}$ Munyagwa, ${ }^{1} \mathrm{~A}$ Greenough. ${ }^{1}$ Women and Children's Health, School of Life Course Sciences, Faculty of Life Sciences and Medicine, King's College London, London, UK; ${ }^{2}$ Kagando Hospital, Uganda

\subsection{6/archdischild-2018-rcpch.268}

Aims Neonatal mortality in Uganda has not improved in the last 14 years and remains between 24 and 27 deaths per 1000 live born infants, which compares poorly to the UK neonatal mortality (2.4 per 1000 live born infants). Our aim 